\title{
Las celebraciones del cincuentenario de la independencia: Lima, julio de 1871
}

\section{The Celebrations of the $50^{\text {th }}$ Anniversary of the Independence: Lima, July 1871}

\author{
Juan Luis Orrego Penagos \\ Universidad de Lima
}

\section{RESUIMEN}

El artículo tiene como objetivo el estudio del programa celebratorio por el cincuentenario de la Independencia del Perú, realizado en Lima, en julio de 1871. Para ello, plantea describir y analizar los acontecimientos, quiénes fueron sus actores y sus roles cívicos y políticos. Asimismo, se plantea interpretar los alcances simbólicos de esta celebración en el proceso de construcción de la nación en el siglo xIx peruano.

\section{Palabras clave:}

Independencia y memoria / Construcción de la nación / Historia de Lima

\begin{abstract}
The article aims to study the celebratory program for the 50th Anniversary of the Independence of Peru held in Lima, in July 1871. For this purpose, it proposes to describe and analyze events, their actors and their civic and political roles. It also analyzes the symbolic scope of this celebration in the process of building the nation in the Peruvian 19th century.
\end{abstract}

\section{Keywords:}

Independence and Memory / Construction of the Nation / History of Lima

\begin{abstract}
os sucesos ocurridos el sábado 28 de julio de 1821, cuando el gene- ral José de San Martín proclamó la independencia del Perú en la plaza de armas de Lima, fueron considerados, a lo largo del siglo XIX, no solo como el inicio de la lucha por la emancipación de la "nación" peruana de la monarquía hispana, sino también el día en que debían celebrarse las fiestas patrias en todo el territorio nacional ${ }^{1}$.
\end{abstract}

De esta manera, se dio inicio a una tradición conmemorativa, al igual que en las demás repúblicas latinoamericanas, como lo ha propuesto Rebecca Earle (2002 y 2005). Cada año se empezó a celebrar, en todos los poblados del país, una fiesta patriótica. Se trataba - como ahora - de un día especial del año, casi sagrado en el altar cívico de la república, en el que quedaban suspendidas todas las actividades rutinarias, tanto públicas como privadas, para que los ciudadanos puedan asistir libremente a unas presentaciones públicas en las que se escenificaba, de manera ritual, no solo el mito fundador de la patria, junto a los héroes fundadores de la "nación", sino también la diferenciación que había entre estos y los ciudadanos espectadores.

Era un ritual que se repetía cada año para renovar los vínculos de los ciudadanos con la patria, una fecha sacralizada. El relato de esta fiesta nos ayuda a entender la construcción del imaginario político del Estado nacional en el siglo XIX, en la formación de una comunidad política que se imagina ya soberana, limitada territorialmente y

1 El 28 de julio fue declarado oficialmente como fecha central de las fiestas cívicas en 1827, durante el gobierno del general José de La Mar (ver Anexo 1). 


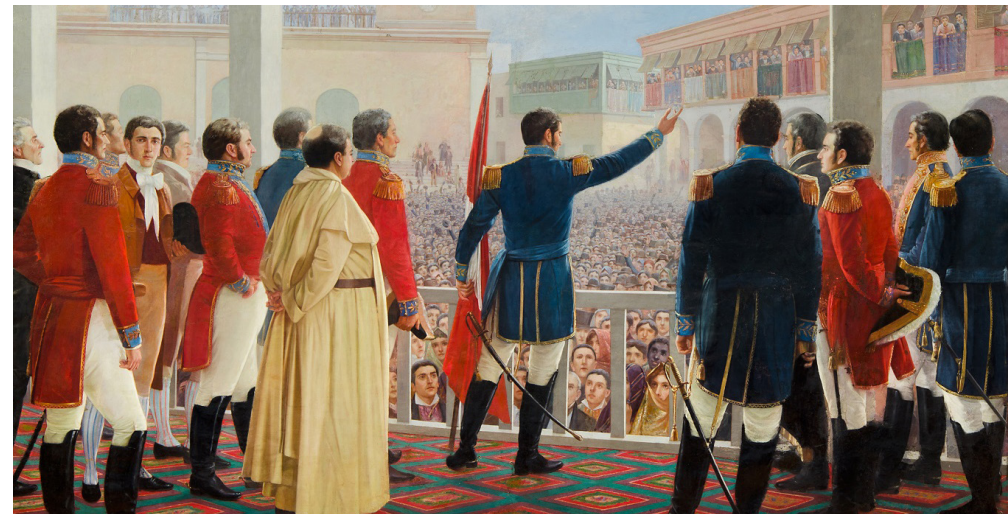

La proclamación de la Independencia, cuadro de Juan Lepiani.

con una historia que avala esa autopercepción.

Este artículo no pretende ser una historia de las fiestas patrias durante el siglo XIX peruano. Solo busca dar testimonio y analizar el ritual de la fiesta patriótica que se desarrolló en Lima durante las fiestas patrias de julio de 1871, cuando se cumplieron cincuenta años del discurso que el general San Martín pronunció en la plaza de armas de la antigua capital del virreinato.

No es una fecha más, sino una efeméride, es decir, un momento crucial para una comunidad que había padecido una "experiencia colonial" y que logró desligarse de tal condición y mantenerse independiente, a pesar de todas las amenazas, internas y externas, que pusieron en peligro la integridad del Estado nacional en plena construcción.

Este tipo de efeméride amerita grandes celebraciones, académicas y populares, para demostrar que el país conserva su independencia y ha podido consolidarse como "nación". Son momentos en los cuales se reflexiona sobre el tipo de "nación" que se ha logrado construir. Asimismo, son ocasiones en que se renuevan los lazos entre sus habitantes para pensar en compromisos comunes. En suma, en estas fechas simbólicas, las comunidades analizan el pasado, celebran el presente y se proyectan al futuro.

Por ello, analizar los aspectos rituales y simbólicos de este tipo de fechas nos ayuda a comprender qué tipo de sociedad se está construyendo. Es desde esta perspectiva que abor- daremos el caso de Lima durante las celebraciones de 1871.

Empezaremos mencionando que el ambiente de esos días, siguiendo los editoriales de los diarios de la época, revela un clima de esperanza. Al parecer, la política de obras públicas emprendida por el gobierno de entonces —el del coronel José Balta (1868-1872) - y el virtual fin de las conspiraciones políticas daban una sensación de bienestar. Hay, por ejemplo, una reiterada mención a los ferrocarriles como símbolo de los nuevos tiempos. Además, el país vivía un clima especial, como nunca antes visto, ya que un gobierno llegaba a cumplir su periodo legal y daba paso a otro, a través de la competencia electoral entre Manuel Pardo (Partido Civil) y José Rufino Echenique, que suscitaba el interés de la prensa.

En este sentido, fue muy ilustrativo el editorial de El Comercio en la víspera del día esperado:

Es muy consolador para el patriotismo, que no llegue jamás el gran aniversario de la Patria, sin que tengamos algo de qué congratularnos. Una gran parte de nuestra vida independiente la hemos pasado en medio de contiendas fratricidas, en medio de la destrucción de todos los intereses en que se basa en el porvenir de los pueblos. Pero, así y todo, no hay año casi en nuestra historia política que no esté iluminado por algún progreso, por un adelanto cualquiera, en las ciencias, en las artes, en el comercio, en la política, en las costumbres, en cualquiera, en fin, de las esferas de la actividad humana. El 28 de julio de $1871 . .$. es acaso el más fecundo de esperanzas para los corazones patriotas. El trabajo y la actividad en todas las esferas, fundan nuevos intereses y mayores fuentes de riqueza, que no como antes limitarán sus beneficios a los pueblos de nuestras costas, sino que vinculándose, poco a poco, a las regiones trasandinas, por los grandes ferrocarriles en construcción, llevarán a ellos también la savia que ha de rejuvenecerlos, y la fraternidad que ha de hacer una verdadera nación de pueblos separados hoy por la distancia, que no se conocen, que se envidian en muchos casos, y que no están ligados por lazo real y verdadero". (El Comercio, 27 de julio de 1871)

Resulta sintomático cómo la prensa, especialmente la que apoyaba la candidatura de Pardo, como El Comercio, subrayara que el país estaba cada vez más cerca de consolidar su orden interno. Del mismo modo, los medios destacaban las riquezas fiscales y los recursos inagotables que la naturaleza le había dado al país como garantía para lograr una paz estable y sólida, y aspirar a ser la segunda república de América, la primera después de los Estados Unidos, lugar que, por aquellos años, nos era arrebatado por Argentina y Chile, naciones ya constituidas y en el camino de lograr las conquistas morales y materiales. El editorial antes aludido culminaba así:

Quiera la fortuna que al conmemorar todos los años el aniversario de nuestra independencia, solo tengamos hoy palabras de esperanza, fundadas como hoy también, en una actualidad que, aunque tranquila, vive el espíritu público agitado por sus más caros intereses. (EI Comercio, 27 de julio de 1871)

Como vemos, la relativa euforia de julio de 1871 no hacía presagiar la bancarrota que encontrarían los civilistas cuando asumieron el poder al año siguiente, producto de los excesos fiscales cometidos durante la administración de Balta por la implementación 
de las obras públicas, especialmente la construcción de los "caminos de hierro" y el levantamiento de los empréstitos de 1871 y 1872 en el mercado de Londres. Tampoco asomaban los evidentes actos de corrupción que acompañaron tal despliegue en infraestructura a lo largo y ancho del territorio nacional. Finalmente, la virtual conquista del orden interno sería amenazada justo un año después con la rebelión de los hermanos Gutiérrez en Lima y, especialmente, con la campaña revolucionaria de Piérola contra el régimen de Manuel Pardo, que terminó opacando las celebraciones por los cincuenta años de la batalla de Ayacucho en diciembre de 1874. En aquella efeméride, prácticamente no hubo tiempo ni dinero ni energía para diseñar un programa de conmemoraciones.

\section{Lima de fiesta}

Con dos días de anticipación, la prefectura de la capital publicó, por bando y con las solemnidades del caso, el programa oficial que se llevaría a cabo los días 28 y 29 de julio (ver Anexo 2). En realidad, las celebraciones comenzaron el jueves 27 por la noche, cuando cientos de limeños colmaron la remozada plaza de armas, totalmente iluminada, y esperaron los fuegos artificiales que retumbaron desde las torres de la Catedral de Lima justo a las 12 para recibir la noche buena. Esta fue la primera muestra de entusiasmo con que debían solemnizarse, durante tres días seguidos, el recuerdo del 28 de julio de 1821, cuando la muchedumbre limeña de aquella generación escuchó, en esa misma plaza, la promesa de la independencia por parte del libertador San Martín.
Al día siguiente, el viernes 28 , desde muy temprano, las bandas militares saludaron el día con el himno nacional. Esa mañana, la juventud tuvo el protagonismo: Ios alumnos y alumnas de todos los colegios y escuelas municipales entonaron la canción nacional mirando hacia el antiguo edificio del cabildo limeño:

Las bandas militares saludan con el himno nacional la aurora de este día glorioso: los alumnos de todos los colegios y escuelas municipales, tanto de hombres como de mujeres, vienen entonando la canción nacional a la casa de la H. Municipalidad. Dijérase que al cantar las estrofas del himno de la patria hacían, como él lo dice el solemne voto de la libertad. El candor de la niñez unido al entusiasmo de la canción, la infantil locura de centenares de niños en la manera de formar el concierto, todo da a ese acto una seriedad que está muy lejos de ser la pueril manifestación del genio juguetón y travieso de los niños. (El Heraldo de Lima, 1 de agosto de 1871)

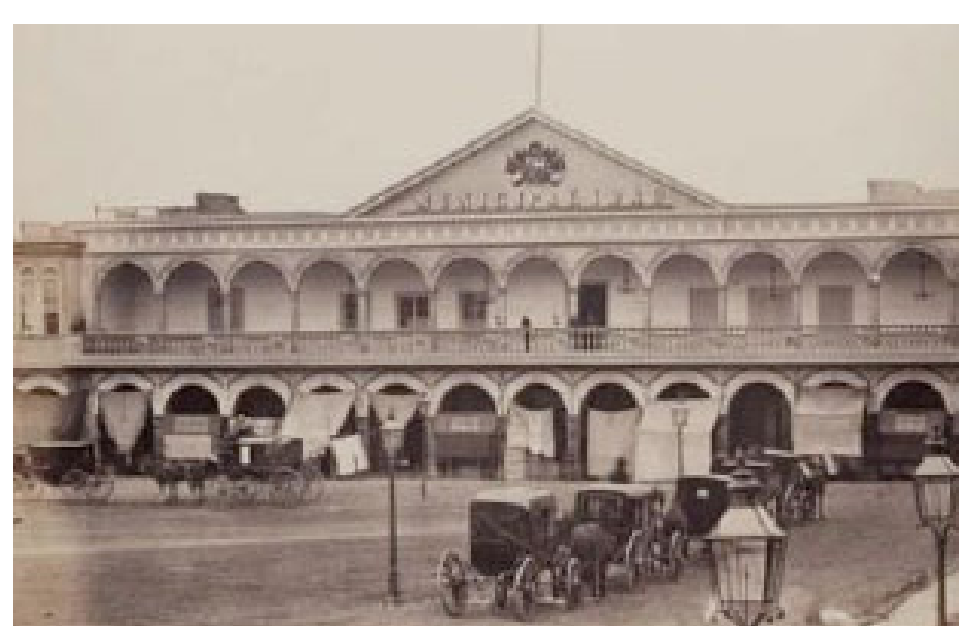

Fotografía de la Municipalidad de Lima en la década de 1870 Fuente: Archivo de la Biblioteca Británica
Después de saludar el 28, el alcalde de Lima, Nemesio Orbegoso, se dirigió, seguido de una numerosa concurrencia, a la inauguración del mercado de La Aurora, junto a la plazuela de Las Nazarenas ${ }^{2}$. Después de abrir las puertas del nuevo centro de abastos, que dejaron penetrar a la muchedumbre, se procedió a bendecir el local. La canción nacional volvió a entonarse y se repartieron flores para las señoras y copas de vino para los caballeros. Después de las nueve de la mañana, el gentío se retiró del mercado y el alcalde se dirigió a inaugurar la escuela municipal de San Pedro.

Luego, las autoridades regresaron al palacio municipal y abrieron la sesión extraordinaria, en la que se dio lectura al Acta de la Proclamación de la Independencia ${ }^{3}$ (ver Anexo 3). A continuación, el alcalde y los regidores distinguieron con una medalla de honor a los alumnos más destacados de los colegios municipales ${ }^{4}$ y se repartieron los premios sorteados el día anterior para las mujeres necesitadas de Lima: se trataba de veintisiete máquinas de

2 El nuevo mercado se levantó en el antiguo Jardín de la Aurora, cuyos propietarios arrendaron a la municipalidad una parte del terreno.

3 El cuerpo municipal estuvo representado por el alcalde (Nemesio Orbegoso), el teniente alcalde (Octavio Tudela), el secretario (Pedro Bernales) y los regidores o síndicos (Bernardo Canevaro, Melitón Porras, Evaristo Gomes-Sánchez, Emilio Piérola, Manuel Dulanto, Melchor García, Juan Manuel Montero y Rosas, Antonio Bentín y Juan Peña (La Sociedad, 1 de agosto de 1871).

4 Fueron los alumnos Francisco Brener, María Luisa Montes, Juan Francisco Granda, Juana Garcilazo, Ignacio Ayllón, Marcelino Sánchez, Rosalía Revoredo, Manuel Salgado y Matilde Mayurí, de las escuelas números 1, 2, 3, 4, 7, 8, 10, 11 y 12, respectivamente (La Sociedad, 1 de agosto de 1871). 
coser destinadas a paliar la infortuna de muchas viudas limeñas ${ }^{5}$.

Por su lado, el presidente Balta, después de asistir al Te Deum, celebrado por el arzobispo José Sebastián de Goyeneche, organizó un banquete en Palacio de Gobierno para los sobrevivientes de las guerras de la Independencia. La invitación se cursó a todos los señores generales, jefes y oficiales vencedores de Junín, Ayacucho y el segundo sitio del Callao. En resumen, se trataba de un gran mariscal, diez generales de división, 31 coroneles, doce sargentos, un empleado de hacienda, veintitrés capitanes, un teniente y dos subtenientes (ver Anexo 4).

El sábado 29 hubo dos actos que tuvieron gran convocatoria. En primer lugar, la solemne "Bendición de la Bandera", la cual era un desfile procesional, en honor al pabellón nacional, organizado por las compañías de bomberos de Lima, integradas, en su mayoría, por ciudadanos de origen extranjero. El desfile se inició en el cuartel de la Bomba de Lima (fundada en 1866, con ocasión del conflicto con España) y tuvo una primera escala en el local de la municipalidad. Según los diarios de la época, conmovía ver a los hijos de diferentes naciones agrupados bajo el mismo estandarte y unidos para defender, con abnegada constancia, la propiedad de los demás. Según el testimonio de El Heraldo de Lima,

las bandas entrelazadas, las herramientas sobre la bomba, todo agrupado con admirable gusto, hacían del carro que conducía la bomba, uno de los más bellos convoyes de hallamos visto. Sin el ruido de las armas, sin el brillo de las armaduras, sin los dorados de la milicia, eran los cuerpos de bomberos, más simpáticos y más cautivadores que los son los batallones cubiertos con sus armas. (1 de agosto de 1871)

De la municipalidad, la comitiva de bomberos se dirigió a la Catedral, donde hubo una solemne ceremonia presidida por el nuncio apostólico: el monseñor Valeri, desde el púlpito, hizo la apología de los bomberos y ensalzó su abnegación por los demás. Después del acto religioso, la municipalidad les ofreció un coctel; tomaron la palabra el alcalde, Giuseppe Ponzoni, jefe de la Bomba Roma, y Ricardo Espiel, secretario de la Bomba de Lima.

Casi al mismo tiempo de este desfile, en la Pampa de Amancaes (en Abajo el Puente, actual distrito del Rímac), los cuerpos del ejército ejecutaron varios ejercicios que fueron seguidos por una gran concurrencia. El testimonio de un diario limeño cuenta el espectáculo que se vio:

Verdaderamente pintoresco era el aspecto de la pampa: la variedad de colores, los batallones de infantería, los escuadrones de caballería, miles de curiosos que se movían en el centro y en las colinas, daban una animación admirable al paseo. A Amancaes no puede irse a estar triste; el que va tiene que alegrarse en esta atmósfera de placer que se respira... Los movimientos que hizo el ejército fueron en general muy buenos: la precisión en ellos y las combinaciones demuestran una disciplina que le hace honor. En el ejercicio de fuego estuvieron algunos batallones admirables: fueron tan precisas las descargas que parecían de un solo fusil y el fuego graneado lo sostuvieron con gran regularidad y durante largo tiempo. La artillería hizo sus movimientos y sus fuegos con acierto y elegancia notables... Todo el mundo accedió a ver el regreso de los del paseo a Amancaes. A las 8 de la noche no había llegado aún a la ciudad la columna de curiosos de Amancaes. (El Heraldo de Lima, 1 de agosto de 1871)

Paralelamente a estos acontecimientos, el Teatro Principal había organizado un programa especial por fiestas patrias, que se inició el jueves 27 y se prolongó hasta el domingo 30 de julio. La velada, que se repitió casi de manera exacta todas las noches, comenzaba a las siete y media. En primer lugar, la Compañía Lírica entonaba el Himno Nacional (todo el proscenio estaba decorado con el pabellón peruano). Luego venía la tragedia, en un acto y en verso, de José Zorrilla, titulada Sofronia. En tercer lugar, venía un "gran concierto" en el jardín, decorado con juegos de aguas, luz eléctrica y estatuas de mármol. El penúltimo acto era la comedia en un acto titulada Asirse de un cabello. Finalmente, se representaba la alegoría en un acto, original del poeta peruano Acisclo Villarán, dedicada a don Manuel A. Fuentes, titulada La corona de laureles. Terminada la alegoría, se interpretaba una apoteosis que representaba a las repúblicas de América (ver Anexo 5). Finalmente, el banquete que el presidente Balta ofreció al cuerpo diplomático residente en Lima se realizó el miércoles 2 de agosto ${ }^{6}$.

\section{Una fiesta patriótica}

Las fuentes que hemos consultado para reconstruir las celebraciones del

5 Las premiadas con máquinas de coser fueron Abelina Segura, T. Herrera, Na. Melena, Magdalena Llagusco, Rosaura Aydé, Gregoria Castillo, Manuela Cortez, Emilia Cristian, Vicenta Ortega, Melchora Illanes, Natividad García, M. Vivanco, Pilar Treviño, Dolores Murillo, María Zguardia, Margarita Mariluz, Celmira Beben, Carolina Cornejo, Juana González, Carmen Consuña, Elisa Descalzo, Emma Vizquerra, Flora Pérez, Manuela Díaz, Manuela Pantoja, Juana Aisborbe, Manuela Salcedo y Elena Cárdenas. Luego, como viudas y parientes de vencedores de la Independencia, recibieron premios de cien soles Eusebia Palomino, Carmen Varela de Negreiros, Magdalena González y Francisca Quiroga; finalmente, con cincuenta soles cada uno, fueron agraciados los siguientes "inválidos de la Independencia": Faustino Valverde, José M. Grados, Mariano Bentín y Manuel Espíritu (La Sociedad, 26 de julio de 1871).

6 Cabe mencionar que hubo un acto programado que no se llevó a cabo: la inauguración del Palacio de la Exposición, en el parque del mismo nombre. Debido a un retraso en la obra, el nuevo edificio recién pudo abrir sus puertas al año siguiente, el 1 de julio de 1872, con una gran exposición con varios países invitados. Ese solo acontecimiento merece un artículo especial. 
cincuentenario de la independencia en Lima nos permiten constatar, al igual que lo que ocurría con las fiestas cívicas en otras capitales latinoamericanas, la existencia de una densa red horizontal de iniciativas festivas, de las cuales el gobierno central estaba prácticamente excluido (Lempériére, 2003). Esta red involucraba a las autoridades municipales, a las escuelas, al clero, a las cofradías y a las asociaciones civiles. El gobierno central distaba mucho de monopolizar la actividad festiva, como ocurrió desde finales de la década de 1890 hasta la actualidad.

De esta manera, la municipalidad cumplía un papel vigilante, directriz y regulador de la celebración. Respecto del espacio urbano dentro del cual se escenificaba la fiesta cívica, este ofrecía un aspecto más congruente con una "república católica" que con una "república liberal-moderna". Como vimos, las celebraciones centrales se llevaron a cabo en la plaza de armas que, a pesar de sus transformaciones, era todavía un espacio que evocaba al pasado virreinal, a la ideología del barroco, cuando la Iglesia dictaba el "orden" del mundo. La plaza de armas tampoco era un espacio "neutral" o "democrático", pues estaba sacralizado y jerarquizado con la presencia de la Catedral, el palacio municipal y la antigua Casa de Pizarro o Palacio de Gobierno. Su trazo se remontaba al siglo XVI y la ubicación de sus edificios públicos obligaba a que los paseos o desfiles cívicos sigan la trayectoria de las procesiones religiosas ${ }^{7}$.
La novedad más destacada en las fiestas del cincuentenario fue la participación de instituciones independientes de las corporaciones tradicionales, como escuelas fiscales, gremios, juntas patrióticas y diversas asociaciones civiles. Muchos ciudadanos, voluntariamente, se encargaban de preparar las fiestas; estos colectivos desempeñaban las mismas funciones que las corporaciones religiosas tradicionales, es decir, se ocupaban de la organización de la fiesta principal del calendario cívico. Sus tareas, en efecto, tenían mucho en común con las de las cofradías, por ejemplo.

Una comisión especial se encargó de recaudar dinero (u otro tipo de aportaciones) entre ciudadanos, empleados públicos y autoridades políticas. Los fondos reunidos estaban destinados a darle el mayor lustre posible a las ceremonias (premiaciones, iluminación de espacios públicos, fuegos artificiales, espectáculos musicales o teatrales, arcos triunfales) y también a financiar "obras de beneficencia" en favor de los deudos de los que pelearon por la independencia o sectores vulnerables de la población limeña (viudas, huérfanos). Los miembros de estas asociaciones cívicas trabajaban en forma estrecha con la municipalidad, con semanas de anticipación, para ultimar todos los detalles de la fiesta.

Otro de los rasgos de las fiestas patrias del XIX, incluida esta del Cincuentenario, son algunas contradicciones en las que cayó (incluso hasta hoy) la elaboración de un ritual cívico. Por ejemplo, como el catolicismo seguía siendo la religión oficial del Estado, era normal la celebración de una misa y Te Deum el 28 de julio ${ }^{8}$. Es más, al Te Deum no solo asistían las autoridades políticas, sino también los integrantes de las organizaciones civiles para recibir la "bendición" de los dignatarios eclesiásticos.

La plaza de armas, entonces, no podía cumplir totalmente el papel de un "espacio neutral", alejado del poder eclesiástico; más bien, evocaba un "espacio sagrado", creado en el siglo XVI por virreyes y arzobispos. En este sentido, la Pampa de Amancaes sí ofrecía el "espacio neutral", donde tenían lugar diversiones populares a lo largo del 29 de julio, con música y maniobras militares, globos aerostáticos, bailes y comida para la plebe limeña.

Es cierto también que había una suerte de "paseo cívico", presidido por autoridades civiles y empleados públicos, que se dirigía, el día 29, desde la plaza de armas a la Pampa de Amancaes. El trayecto, que recorría el puente de piedra sobre el río Rímac, seguía por el barrio de San Lázaro y terminaba en Amancaes, se adornaba de arcos o templetes alegóricos; también se escuchaban gritos a la patria 0 a los héroes. El paseo, también llamado "procesión", llevaba el sello de la ambigüedad, puesto que el gentío también portaba toldos u otras insignias utilizados en las fiestas religiosas. Además, sabemos que, desde

7 A lo largo del siglo xIX, las fiestas cívicas tuvieron que competir con las religiosas, todavía más numerosas que las primeras. Sabemos que, desde los tiempos de San Martín o del Protectorado, las autoridades civiles hicieron esfuerzos para dar vida a las fiestas cívicas a través de decretos u otros mecanismos de convocatoria, según las urgencias del momento. Así, poco a poco, se pudo escenificar una identidad republicana más conforme a los ideales del liberalismo y del patriotismo cívico. El proceso, sin embargo, según Annik Lempériére (2003), encontró serios obstáculos en América Latina. En la Ciudad de México, por ejemplo, desde principios de la era republicana, las fiestas de la Independencia, teóricamente cívicas y profanas, no pudieron sacudirse del componente religioso.

8 Podríamos afirmar que las fiestas patrias eran también una fiesta de la Iglesia. Los periódicos consultados demuestran que los actos litúrgicos eran indispensables para la celebración nacional. Aunque todos los templos de Lima participaban, era en la Catedral donde se concentraban los esfuerzos en busca de la bendición divina. Había repiques de campanas en todas las iglesias o parroquias, al amanecer, al mediodía y al atardecer. Los actos principales tenían lugar el 28 de julio: el sermón, la misa y el canto del Te Deum. El sermón pronunciado debía exaltar los valores republicanos e invocar la bendición divina para los propósitos de nuevo orden constituido. Por su lado, la misa, uno de los momentos más solemnes del ritual católico, representaba el clímax de los actos litúrgicos en honor de la fiesta nacional. A la misa y el sermón asistían solo los que tenían invitación del municipio: autoridades civiles, militares y eclesiásticas, así como las familias más notables de la capital. En suma, la élite y el poder político esperaban que los ciudadanos, católicos en su gran mayoría, se involucraran en la victoria de la Independencia y al asentamiento de la república, un proceso que era bendecido por el Altísimo y que, a fin de cuentas, materializaba los principios cristianos de justicia y libertad. 
los tiempos del virreinato, los limeños hacían el mismo recorrido para acudir a reuniones de esparcimiento en la Alameda de los Descalzos o en las Pampas de Amancaes.

En Lima, al igual que en otras ciudades de América Latina, como ya lo han indicado Geovanny Cabrera y Ligia Barbesi (2008), los actos de celebración se iniciaban desde el día de la víspera, con "repique general de campanas" de todas las iglesias, y música. Este acto podía iniciarse desde el amanecer, o al mediodía, 0 al caer la tarde, 0 bien repetirse las tres veces. Los actos quedaban formalmente inaugurados con la publicación de bandos en plazas 0 plazuelas a cargo de las autoridades municipales; estos anunciaban el decreto que ordenaba la celebración de la fiesta, y debían publicarse con la suficiente antelación. En la noche de la víspera, la celebración podía ser fastuosa, con iluminación de las calles y casas, fuegos artificiales y lanzamiento de globos aerostáticos, augurando la fastuosidad que traería el día de la fiesta desde el amanecer hasta terminar el día. Las familias debían barrer los frentes de sus casas y adornarlas con los colores de la bandera e iluminarlas. Como el día nacional era feriado, se dedicaba por entero a la celebración, y toda la ciudad se congregaba en la plaza de armas, centro de los festejos. Los actos se iniciaban al alba, y eran saludados con repique general de campanas y tiros de artillería.

Las celebraciones por el cincuentenario de la independencia del Perú llevadas a cabo en Lima, corresponderían a la formación del sistema ideológico-simbólico de la construcción del Estado-nación, como sugieren José Burucúa y Fabián Campagne $(2003)^{9}$. En primer lugar, ya la historiografía que nació en el siglo XIX logró diseñar el primer relato (una "buena historia", basada en hechos reales) que los peruanos tuvieron sobre el pasado y valoró la independencia como una gesta necesaria y heroica. Ese fue el objetivo de las páginas que escribieron Mariano Felipe Paz Soldán y Manuel de Mendiburu.

Pero a este discurso, supuestamente racional y científico, amparado por los estándares del positivismo, se añadió la actividad mitopoiética, que se plasmó, principalmente, en los cambios que experimentó la capital de la república, a partir de la segunda mitad del XIX, respecto de su plaza mayor, el nombre de sus calles, la colocación de monumentos, el derribo de sus murallas coloniales y la creación de nuevos espacios públicos "republicanos"10. Lima, como muchas capitales latinoamericanas de su tiempo, quería romper con su aspecto virreinal y convertirse en una urbe moderna, a la "europea", y que sus espacios públicos evoquen la historia y la geografía nacionales ${ }^{11}$.

Ahora, la historia empezó a ser leída no solo en las obras de Paz Soldán y Mendiburu 0 en los textos escolares sino también en una trama figurativa e iconográfica mediante otros documentos (calles, plazas, museos) que se insertaban en el tejido material de una ciudad en plena transformación gracias a los recursos generados por del guano, manejados por una elite modernizadora. En este sentido, la celebración del Cincuentenario pretendía exhibir una riqueza y una coherencia que el proyecto republicano y la construcción de la nación eran temas ya concluidos 0 , por lo menos, en vías de ser acariciados.

9 Según ambos autores, el sistema ideológico-simbólico en la construcción de la nación en América del Sur abarcaría desde la década de 1860 hasta la segunda mitad del siglo XX. En el caso peruano (y esta es una observación nuestra), este proceso sufriría un quiebre importante en 1879, cuando estalló la Guerra del Pacífico. La derrota frente a Chile obligaría a replantear los valores y los símbolos sobre los cuales levantar la nación.

10 Asumimos la mitopoiesis como el proceso mediante el cual un colectivo social configura o trae al presente una serie de mitos, los cuales usa como escudos espirituales de sus acciones en un momento dado. En el siglo XIX, hubo el interés en crear mitos que pudieran dar consistencia a nuevos modelos y provocar un cambio de orden social, político, económico, y cultural con la finalidad de formar un nuevo sujeto social. El concepto de mitopoiesis gira también en torno a la idea de héroes que, en un momento dado, pueden convertirse en mitos, configurando de alguna manera la identidad de un colectivo social.

11 Burucúa y Campagne (2003) relacionan el aspecto "monumental" de la actividad mitopoiética con las transformaciones urbanas (nuevos espacios públicos) realizadas por las elites para formar, nutrir una memoria colectiva. De ahí que llaman monumental a esta etapa. Pero, en cierto modo, el calificativo también conservaría su validez a los espacios historiográficos y literarios, pues los grandes relatos de la historia y de la ficción fueron también monumenta en el sentido genérico de todo aquello que es capaz de suscitar un recuerdo. Serían los equivalentes de los monumenta rerum gestarum de los que hablaba Cicerón para señalar la totalidad de la cultura antigua y la herencia inmaterial de Roma. 


\section{Bibliografía}

Burucúa, J., y Campagne, F. (2003). Mitos y simbologías nacionales en los países del cono sur. En A. Annino y F.-X. Guerra (coords.), Inventando la nación. Iberoamérica, siglo xIX (pp. 443-474). México, D. F.: Fondo de Cultura Económica.

Cabrera, G., y BarbesI, L. (2008). Construyendo la patria: fiestas nacionales en Maracaibo, 1834-1862. Mañongo, XVI(30), 133-166.

Earle, R. (2002). "Padres de la Patria" and the Ancestral Past: Celebrations of Independence in Nineteenth-Century Spanish America. Journal of Latin American Studies, 34(4) 775-805.

EARLE, R. (2005). "Sobre héroes y tumbas": National Symbols in Nineteenth-Century Spanish America. Hispanic American Historical Review, 85(3), 375-416.

LempéRIÉRE, A. (2003). De la república corporativa a la nación moderna. México (1821-1860). En A. Annino y F.-X. Guerra (coords.), Inventando la nación. Iberoamérica, siglo xIX (pp. 316-346). México, D.F.: Fondo de Cultura Económica.

Oviedo, J. (1861). Colección de leyes, decretos y órdenes publicadas en el Perú desde el año de 1821 hasta 31 de diciembre de 1859. Lima: Felipe Bailly (editor) y Librería Central Portal de Escribanos.

\section{Periódicos}

El Comercio

El Heraldo de Lima

La Sociedad

\section{Anexos}

\section{ANEXO 1}

\section{EL CONGRESO GENERAL}

\section{Constituyente del Perú}

\section{Considerando:}

Que la multitud de fiestas cívicas causan gastos innecesarios, y acarrea a los ciudadanos perjuicios de retardo en la administración de Justicia y suspensión de sus ocupaciones útiles;

\section{Decreta:}

Art. Único. Todas las fiestas cívicas de la República quedan reducidas a una sola, fijándose para su celebridad el día 28 de Julio, como aniversario de la jura de la Independencia.
Comuníquese al Poder Ejecutivo para que disponga lo necesario a su cumplimiento, mandándolo imprimir, publicar y circular.

Dado en la Sala del Congreso, en Lima, a 16 de Noviembre de 1827.

Tomás Diéguez, presidente.- Juan Antonio Távara, Diputado secretario.- José Villa, Diputado secretario.

Por tanto ejecútese, guárdese y cúmplase.

Dado en Palacio de Gobierno, en Lima, a 19 de Noviembre de 1827.

José de La Mar

Por orden de S. E. Francisco Javier Mariátegui

Fuente: Oviedo, J. (1861). Colección de leyes, decretos y órdenes publicadas en el Perú desde el año de 1821 hasta 31 de diciembre de 1859. Lima: Felipe Bailly (editor) y Librería Central Portal de Escribanos, tomo IV, p. 362. 


\section{ANEXO 2}

\section{PREFECTURA DE LIMA}

\section{Por cuanto:}

El 28 del presente mes de julio es el $50^{\circ}$ aniversario de la independencia del Perú, hecho glorioso que debe celebrarse con demostraciones públicas de regocijos. Por tanto, y de conformidad con lo dispuesto en la ley de 16 de noviembre de 1827;

\section{Decreto:}

Art. $1^{\circ}$ El 28 de julio es día de fiesta cívica dedicada a la conmemoración y solemnidad de la proclamación y juramento de la independencia del Perú, cuyos gloriosos sucesos tuvieron lugar en esta capital los días 27 y 28 del mes de julio de 1821.

Art. $2^{\circ}$ Todos los vecinos podrán manifestar su patriotismo y regocijo, en los días 28 y 29 del actual, del modo que les sea posible, con tal que no se afecte el orden y tranquilidad pública.

Art. $3^{\circ}$ Las autoridades y los empleados departamentales concurrirán al salón de palacio el citado día 28 a la hora de reglamento con el objeto de acompañar a S.E. el presidente de la república a la misa solemne de gracia, que tendrá lugar en la Iglesia Catedral.

Art. $4^{\circ}$ En los mismos días 28 y 29 se enarbolará el pabellón nacional en todos los establecimientos públicos y particulares, cuyas fachadas se adornarán convenientemente.

Art. $5^{\circ}$ En las noches del 27 y 28 se quemarán en la Plaza de Armas vistosos fuegos artificiales y habrá repique general de campanas en los periodos que determina el reglamento de policía.

Art. $6^{\circ}$ El subprefecto de la provincia queda encargado del cumplimiento de este decreto. Imprímase, publíquese por bando y fíjese en los lugares de costumbre.

Dado en la casa prefectura de Lima a 26 de julio de 1871,

Antonio Rodríguez Ramírez

Miguel Balbontin, Secretario

Fuente: La Sociedad, 26 de julio de 1871.

\section{ANEXO 3}

\section{SESIÓN EXTRAORDINARIA DEL VIERNES 28 DE JULIO DE 1871}

Abierta la sesión con asistencia de los señores Orbegozo (Alcalde) y Regidores Canevaro, Porras, García, Dulanto, Varela y Valle, Soyer, Montani y Peña Secretario, se dio lectura al acta de la proclamación de la Independencia.

El señor Alcalde indicó que iba a proceder a distinguirse con una medalla de honor al alumno que en cada uno de los colegios municipales de ambo sexos se hubiese distinguido más por su moralidad y contracción empezándose a distribuir aquellos por los colegios de niñas resultaron agraciados los siguientes alumnos:

\section{Escuela $n^{\circ}$ 1, Dn. Francisco Brener}

Escuela $n^{\circ} 2$, Srta. Maria Luisa Montes

Escuela $n^{\circ} 3$, D. Juan Francisco Granda

Escuela $n^{\circ} 4$, Srta. Juana Garcilazo
Escuela nº 7, Dn. Ignácio Ayllón

Escuela $n^{\circ}$ 9, Dn. Marcelino Sánchez

Escuela $n^{\circ} 10$, Srta. Rosalía Revoredo

Escuela $n^{\circ} 11$, Dn. Manuel Salgado

Escuela $n^{\circ} 12$, Srta. Matilde Mayurí

En seguida se procedió a distribuir las donaciones de a veinte soles entre las personas agraciadas según [el] número que les correspondía, disponiéndose el martes las que no se habían presentado.

Se acordó igualmente que el martes ya indicado se entregaran las máquinas de coser a las personas que las obtuvieron cuya lista nominal existe en la junta.

Se procedió después a entregar a las familias pobres de vencedores en las gloriosas jornadas de la independencia las cuotas que se les acordó y se distribuyó también a los vencedores inválidos como individuos de tropa en las referidas jornadas las sumas con que resultaron igualmente favorecidos. 
Habiendo algunos otros inválidos y familias pobres quedando excluidos de la gracia por no haberlos favorecido la suerte los señores regidores municipales formaron una bolsa de su propio peculio y la distribuyeron proporcionalmente entre dichas personas.

Terminado el acto se cerró la sesión,

Nemesio Orbegoso [rúbrica]
Melitón Porras [rúbrica]

S. Soyer [rúbrica]

Juan Manuel Montero [rúbrica]

Manuel Dulanto [rúbrica]

Fuente: Acta de sesiones del Cabildo de Lima.

\section{ANEXO 4}

\section{LISTA OFICIAL DE VENCEDORES DE LA INDEPENDEN- CIA EN 1871}

\section{General de División:}

Manuel Aparicio

\section{Generales de Brigada:}

Manuel de la Guarda, Manuel Ignacio de Vivanco, Juan J. Arrieta, Juan Antonio Pezet y Baltasar Caravedo

\section{Coroneles:}

Pedro Torres, Juan C. Mendoza, Joaquín Torrico, Manuel Arnáez, Juan Espinoza, Rafael Grueso, Francisco Alvariño, Manuel Vidaurre, José A. Robles, Juan Rubina, Bonifacio Franco, José Murillo y Agustín Mispireta

\section{EMPLEADOS DE HACIENDA:}

Manuel R. de la Rosa O'Phelan, vocal del Tribunal del Consulado

\section{Coroneles, tenientes CORONELES:}

Juan G. Evia, José Ponce de León, Manuel Uribe, José del C. Gallegos, Nicolás Ormaza, Lorenzo Tudela, Policarpo Arana, Tomás Collazos, Felipe Santiago Romero, Pablo Horna, José Ramón Andrade, José M. Gonzáles, Lucas, Zela, Manuel T. Coloma, Mariano G. Robledo, Fermín Calderón, Casimiro Negrón y Francisco Bolívar

\section{TENIENTES CORONELES, SARGENTOS MAYORES:}

Toribio Barrantes, Manuel Mendoza, Manuel Garro, José M. Agüero, Manuel Amador y Narciso Tudela

\section{SARGENTOS MAYORES, CAPITANES:}

Pedro P. Álvarez, José M. Cruz, Francisco Hernández, Simón Salas, Cecilio Jaro, Casimiro Gómez, Manuel La Torre, José
Mariano Alvarado, Pedro Reyes, Julián Chirinos, Melchor Solar, Ceferino de la Puente, José Gavirondo, Miguel Ramírez y Luis Llaque

\section{Capitanes teNIENTES:}

Manuel Terruel, Juan Miranda, Felipe S. Cuenta y José Nieves

\section{SuBTENIENTE:}

José Contreras

\section{TENIENTE:}

Gregorio 0jeda

\section{Veteranos:}

Señor Gran Mariscal Antonio Gutiérrez de la Fuente Generales de División José Rufino Echenique y Fermín del Castillo

Generales de Brigada José Miguel Medina y José Allende

Coroneles Pedro José Torres, José Benigno Carrillo, José Gonzáles Taramona, Asencio del Carpio, Francisco Deustua, Mariano Gomez Flores, Felipe Santiago La Rosa, José Panizo, José Gabriel Ríos, Bernardo Bermúdez, Agustín del Solar y Pedro Vidaurre

Coroneles y tenientes coroneles Lorenzo Iraola, José Miguel Cárdenas, Pedro Palacios, José Julián Ugarte, José Gonzáles García, Pablo Zapata y Antonio Tardío

Sargentos mayores Manuel Morales, Francisco Gonzales Mogaburu, Juan José Ruiz, Mariano Salaverry y Luis Arias

Capitanes Felipe Montestruque, Ignacio Izquierdo, José Vallejo, Ángel M. Boza y José Antonio Alvarado

Tenientes Gregorio Munares, Anselmo Matos, Nicolás Leyva, Gabriel Astete y Cipriano Maldonado 


\section{RETIRADOS DISPERSOS:}

Coronel Ambrosio Taboada

Tenientes coroneles Estanislao C. y Geray y Juan B. Cortegana

Sargento Mayor Manuel G. y Ramírez

Tenientes Timoteo Cerral y León Foronda

RETIRAdOS EN PLAZA:

Coronel Mateo Estrada

\section{INVÁLIDOS EN PLAZA:}

Coronel Lorenzo L. Gonzales

Capitán Jacinto Nalvarte

Mayores Andrés Posada y José Terán

\section{INVÁLIDOS DISPERSOS:}

Coronel Manuel Gonzales Mugaburu

Fuente: El Comercio, 27 de julio de 1871.

\section{ANEXO 5 \\ PROGRAMA EN EL TEATRO PRINCIPAL POR FIESTAS PATRIAS (1871)}

\section{Jueves 27}

1. “La Canción Nacional” cantada por la Compañía Lírica (decoración nueva representando todo el proscenio el pabellón peruano)

2. La tragedia en un acto y en verso de José Zorrilla titulada "Sofronia"

3. "Gran concierto" en un jardín en el que habrá pilas, luz eléctrica, estatuas, etc.

4. La comedia en un acto titulada "Asirse de un cabello"

5. La alegoría en un acto, original del poeta peruano Acisclo Villarán y dedicada a Manuel A. Fuentes, "La Corona de Laureles". Terminará la alegoría con una hermosa apoteosis que representará a las repúblicas de América

\section{VIERnes 28}

1. "La Canción Nacional” cantada por la Compañía Lírica (decoración nueva representando todo el proscenio el pabellón peruano)

2. La comedia en un acto, escrita expresamente para la señora Romedal, por el señor Cipriano Martínez, titulada "Las diabluras de Perico"
3. "Gran concierto" en un jardín en el que habrá pilas, luz eléctrica, estatuas, etc.

4. La comedia en un acto titulada "No hay humo sin fuego"

\section{SÁbado 29}

1. “La Canción Nacional” cantada por la Compañía Lírica (decoración nueva representando todo el proscenio el pabellón peruano)

2. La comedia en un acto titulada "Pobres mujeres"

3. "Gran concierto" en un jardín en el que habrá pilas, luz eléctrica, estatuas, etc.

4. La comedia en un acto "El vecino de enfrente"

\section{Domingo 30}

1. "La Canción Nacional" cantada por la Compañía Lírica (decoración nueva representando todo el proscenio el pabellón peruano

2. El grama en un acto "La Sospecha"

3. Gran concierto en un jardín en el que habrá pilas, luz eléctrica, estatuas, etc.

4. La comedia en un acto "La mosquita muerta"

Fuente: El Comercio, 26 de julio de 1871 